\title{
HUELLAS DEL CAPÍTULO 13 DEL ULYSSES EN UNA NOVELA DE ESTHER TUSQUETS ${ }^{1}$
}

\author{
Mónica María Martínez SaRiego \\ Universidad de Las Palmas de Gran Canaria \\ monicamartinezsariego@gmail.com
}

\section{RESUMEN}

El presente artículo aborda la posible relación entre el episodio joyceano de Nausícaa (Ulysses, 1922) y una de las intrigas secundarias en la novela de Esther Tusquets Varada tras el último naufragio (1980). El examen de ambos textos revela coincidencias formales y conceptuales que hacen plausible la influencia de la una sobre la otra. Se tienen también en cuenta las declaraciones de la propia Tusquets sobre Joyce.

Palabras Clave: Joyce, Tusquets, Nausícaa.

\section{AbSTRACT}

This article examines the relationship between the joycean episode of Nausicaa (Ulysses, 1922) and one of the subplots in Esther Tusquets' Varada tras el último naufragio (1980). Formal and conceptual evidence is drawn from the texts to support the view that the Spanish novel is probably based upon this chapter of Joyce's masterwork. Tusquets' statements about Joyce are also taken into account.

KeY Words: Joyce, Tusquets, Nausicaa.

\footnotetext{
${ }^{1}$ Una primera versión de este trabajo fue presentada en los XVII Encuentros James Joyce (Abril 2006).
} 
«Nausícaa», capítulo decimotercero del Ulysses, constituye una singular reelaboración contemporánea del canto VI de la Odisea. En un mismo escenario de mar y arena, Leopold Bloom, náufrago espiritual, se nos aparece como reencarnación del héroe homérico, y la soñadora Gerty MacDowell, que llega a la playa acompañada de otras jóvenes y que, conmovida por el aspecto triste del desconocido, se apresta a «socorrerlo», es fiel heredera de Nausícaa, la joven princesa feacia que brinda su ayuda, y su amor, al desolado Ulises.

En la literatura española del siglo XX encontramos también reescrituras novelísticas del episodio homérico, filtradas, algunas veces, por la mirada contemporánea de James Joyce, como sucede, según creemos, en una de las intrigas secundarias de Varada tras el último naufragio (1980) de Esther Tusquets. En esta obra, Pablo, sumido en la insatisfacción y el descontento de sus cuarenta años, observa en la playa a dos hermosas jóvenes que, según imagina, desarrollan una mágica pantomima en su honor, y de las cuales una, agresiva y magnífica, sin quebrar la atmósfera de danza y de exhibición, con el andar peculiar de las muchachas muy hermosas que no han cumplido todavía los veinte años, se le acerca para pedirle que le encienda un cigarrillo. Este gesto da pie a una fugaz aventura de verano en la que el hombre reencuentra, por unos instantes, su propia adolescencia, pero que al final, en el momento de la despedida, acaba representando «el definitivo final donde se entierra para siempre, junto a la juventud, la posibilidad de soñar y de levantar el vuelo» $(228)^{2}$.

Aunque un abismo en el tono y en la intención separa las dos recreaciones contemporáneas del episodio homérico, a nivel de los detalles hay suficientes evidencias como para hacernos pensar que existe un vínculo entre ellas, sobre todo si tenemos en cuenta que, sólo cuatro años antes de la aparición de Varada, Esther Tusquets había publicado en Lumen, editorial de su propiedad, la traducción del Ulysses llevada a cabo por J. M. Valverde $^{3}$. El examen detallado de las declaraciones de la autora y de las diferentes recreaciones del episodio de Nausícaa que en este trabajo acometemos nos permitirá pronunciarnos al respecto con mayor claridad.

\section{El CAPÍtUlo 13 del UlYSSES: «NAUSICAA»}

Aunque hay quienes, como Jose María Valverde (1982: 94, 104), tratan de minimizar la importancia de los paralelos homéricos del Ulysses, planteando, entre otras cosas, que la obra ganaría sentido en caso de que prescindiéramos de las referencias clásicas ${ }^{4}$,

2 Se citan los pasajes de Varada tras el último naufragio (1980) a partir de la edición en Anagrama (Tusquets, 1998).

3 Todas las citas del Ulysses corresponden a la sexta edición de la traducción de J.M. Valverde en Joyce (2001), que sigue la edición crítica de H. W. Gabler (New York: Garland, 1984) y que fue, si exceptuamos la versión argentina de J. Salas Subirat (1945), la primera en verter el texto joyceano al castellano. No incluimos en nota el texto original inglés porque para la cuestión concreta que estudiamos — la recepción de la obra de Joyce en una autora que no dominaba la lengua inglesa - es irrelevante. Una reseña sobre esta traducción puede verse en Bernáldez Bernáldez (1977). Sobre las diferentes traducciones de esta obra joyceana al español, cfr. García Tortosa (1994: 22-28).

${ }^{4}$ El referente clásico, según Valverde, aparece sólo en el título de la novela, pues el texto mismo no dice nada que lleve a las alusiones clásicas en cuestión. Si cada capítulo tomó en principio un emblema odiseico o 
las claves hermenéuticas invocadas por sus primeros escoliastas ${ }^{5}$ se han impuesto por varias razones, como la conveniencia didáctica o académica, o la tendencia natural a superar y dominar los conflictos anárquicos de la época contemporánea sometiéndolos a venerables moldes heredados de un pasado que se exalta, y hasta se canoniza, como digno, poderoso y honorable. El notable valor de las alusiones homéricas lo pone de relieve, por ejemplo, Richard Ellman, tal vez el mejor biógrafo de Joyce, que ilustra su importancia, precisamente, con el ejemplo de «Nausícaa»:

I imagine Joyce as reading and re-reading Homer with a special delight because of his own ulterior motivation. He testified to his pleasure in the episode where Ulysses, grizzled and scarred, or as Joyce said to a friend, «perhaps baldheaded», yet still eligible, is a suppliant before the virginal seventeen-year-old Nausicaa. That the shipwrecked man should be naked made Joyce think of emphasizing what he called «the parts that mattered» by Gerty's coyness about them. Homer's hero, after having covered these parts with a leafy branch, addresses the princess in fulsome style, «I kneel to thee, Queen, are you goddess or mortal?» This is blarney but it works. Nausicaa responds to these attentions by indicating how very mortal she is, so mortal indeed that she is quite prepared to marry him if asked. Joyce adapts Homer so that Gerty's mortal-immortal being is evoked by a similar confusion between the original Gerty seated on the strand and the Virgin Mary ensconced in the Star of the Sea church nearby. Coy miss and sacred myth interact. Votive offerings are made to the two shrines simultaneously. These elements were present in Homer, though admittedly latent. Joyce not only brings them to the surface, but couches them in a style which, at once adulatory and lubricious, seems also to be asking with Ulysses, «Are you goddess or mortal?» (1977: 33) .

El destino de las versiones contemporáneas de los mitos es justamente éste: sacar a la luz aspectos latentes en los textos clásicos ${ }^{7}$, convirtiéndolos, a veces, en vehículo de preocupaciones e ideologías modernas. No debe perderse de vista en este sentido que, en lugar de recurrir a la mitología para ennoblecer la vida contemporánea, Joyce, que lleva a su culmen una tendencia apreciable también en otros escritores simbolistas, emplea el mito griego para degradarla, para mostrar, por contraste con el heroísmo o la belleza de la leyenda clásica, cuán sórdidos se han hecho los hombres y las mujeres de hoy. El principal objeto del paralelo épico en el Ulysses es, no en vano, contraponer el fuerte, noble y majestuoso pasado con el sucio, pobre y brutal presente, en que todo es porquería y humillación ${ }^{8}$. Así, frente a la dulzura idílica del episodio homérico, en el que Ulises, recu-

simplemente clásico, fue sólo a modo de chiste o de referencia en muchos casos traída por los pelos. Recuerda el traductor, además, que los titulillos de cada capítulo aparecieron en la publicación por entregas, pero no en el libro (1982: 94). Sobre la inspiración homérica del Ulysses, cfr. las oportunas, aunque breves, apreciaciones de Highet (1949: 505-507).

${ }^{5}$ Estas referencias, que, como el lector bien sabe, no son tan sólo las correspondencias con la Odisea, las recopila y comenta con detalle el crítico francés Jacquet (1974).

${ }_{6}$ Aunque Ellman no se refiere a ello, ha de anotarse que, en lo que a Homero respecta, hablamos de hipotexto en sentido amplio, porque, más que en el autor griego propiamente dicho, Joyce se inspiró en sus traductores. Cfr. a este respecto Kenner, que considera el Ulysses «museo de Homeros» (1969: 267).

7 Sobre cómo las versiones modernas explicitan aspectos latentes en el poema griego - especialmente la vacilación entre la esposa que espera y la tentadora belleza de la joven-, cfr. las apreciaciones de Stanford (1963: 54-55, 191-193) y el breve comentario de Frenzel (1994: 350-351).

${ }^{8}$ A los aspectos escatológicos de este capítulo deben añadirse los obscenos y pornográficos, que han hecho correr mucha tinta. A este respecto cfr. Law (1990), Leckie (1996) y, más recientemente, Potter (2004). 
bierto de costras salinas, halaga a la princesa Nausícaa, retoño de mujer, comparándola con un brote de palmera que ha visto en Delos, junto al altar de Apolo; y en el que ésta, encandilada, le brinda la oportunidad de gozar de un amor inocente y virginal, el texto de Joyce nos presenta a un hombre maduro que, contemplando la ropa interior de una muchachita insinuante a la orilla del mar, se entrega disimuladamente al onanismo. Salvo la parte final, que es «palabra interior» de Bloom, casi todo el capítulo está compuesto, muy apropiadamente, como caricatura de la barata literatura sentimental de la época, a la que la muchacha es aficionada ${ }^{9}$, y con un estilo que el propio Joyce definió como «ñoño mermeladoso braguitoso (alto là) con efectos de mariolatría de incienso, masturbación, berberechos estofados, paleta de pintor, cháchara, circunlocuciones...» ${ }^{10}$. Nos hallamos, en suma, ante una «parodia cruel de todo el romanticismo y sentimiento que envuelven al episodio homérico» (Serrano Sordo 1994: 255) ${ }^{11}$.

\section{Paralelos del capítulo 13 del UlySSES y VARADA tRAS EL Último NaUfraGio}

Ya hemos comentado que en Varada tras el último naufragio (1980), tercera novela de la trilogía compuesta por Esther Tusquets, hay una intriga secundaria, —aunque de vital importancia por su repercusión en el desenlace de la trama-, en la que una misma escena a orillas del mar, la exhibición de dos muchachas en la playa ante un hombre maduro que no deja de contemplarlas, se nos presenta como un nuevo avatar del mito de Nausícaa, plausiblemente filtrado por la versión joyceana. El episodio, que carece de la dulzura idílica del griego, omite, en líneas generales, toda referencia a los detalles escabrosos con que se explaya Joyce, pero conecta con el texto del irlandés, sobre todo, en lo que respecta a los detalles en el empleo de un mismo escenario, en la descripción de la belleza juvenil, en el juego de miradas y de suposiciones mutuas, en la conmovedora cursilería de la muchacha, y en la apesadumbrada reflexión final del hombre.

\footnotetext{
${ }^{9}$ Hablamos tanto de las revistas para jóvenes como de la novela victoriana romántica, especialmente de The Lamplighter y de Mabel Vaughan, obras de Maria Cummins que promovían los valores de la domesticidad. Aunque hay quienes han sugerido que Joyce recurrió a cartas y memorias escritas por mujeres reales o de ficción - las novelas de Richardson y otras cuantas del siglo XVIII inglés-, los paralelos más evidentes son, en efecto, los estudiados por Devlin (1985), para quien toda la primera parte del capítulo es parodia de The Lamplighter. Desarrolla esta cuestión Kupinse (1999), que analiza cómo las nociones de femineidad, domesticidad e identidad nacional quedan afectadas por la caricatura joyceana. La deconstrucción del discurso de la domesticidad es también abordada por Schwarze (2002: 117-141). El encuentro entre Bloom y Gerty podría considerarse, en fin, ejemplo de autoparodia, pues la contemplación orgásmica de la joven Mac Dowell conecta, como tantas veces se ha subrayado, con el momento epifánico en que el Stephen de A Portrait of the Artist as a Young Man queda extasiado frente a la doncella-pájaro a la orilla del mar. Cfr., por ejemplo, Ellman (1982: 370 y 385).

${ }_{10}$ Sobre el estilo en este episodio, cfr. McGee (1987), que aborda la cuestión desde la perspectiva de los estudios de género. El capítulo se presta especialmente a ello, ya que es «the only episode in Ulysses with an equally male and female focus» (Pearce, 1996: 105).

${ }^{11}$ El propio Serrano Sordo (1994) estudia con detalle los mecanismos de la parodia en este episodio del Ulysses. También es interesante la apreciación de Norris, que, haciendo alusión al mito de la manzana de la discordia, se refiere, junto con otras cuestiones, al hecho de que «Bloom, as Paris, will choose Gerty because she impersonates classical statuary but offers him, unlike the unyielding museum goddesses, a peek at her bottom» (1998: 44). Las oposiciones entre éxtasis espiritual y carnal apreciables en el capítulo 13 del Ulysses son estudiadas por Smith (1990). La metafísica del coito que subyace al mismo es analizada por Bishop (1999).
} 


\subsection{La belleza adolescente}

A pesar de la cojera — «that one shortcoming»— con que Joyce desmitifica la belleza de Gerty una vez que ha concluido el desahogo erótico de Bloom, que hace aparecer a la muchacha como un ídolo con pies de barro — «an idol with damaged feet» (Higgins 1997: 56) ${ }^{12}$ —, las dos jóvenes se caracterizan, en líneas generales, por su hermosura deslumbrante de hembra que ha alcanzado una plenitud fugaz e irrepetible y que tiene, como mayor encanto, una cabellera larga y turbadora que se le desparrama en bucles sobre los hombros. Escribe Tusquets:

Fue sólo una ilusión, el espejismo de una mañana mágicamente luminosa, desmesuradamente azul, con aquella muchacha balanceando su cuerpo soberbio — bruñido, liso, moreno, con raras calidades de porcelana o de cristal — junto a la portezuela abierta, el cabello cayéndole pesado, en rizos cobrizos, a lo largo de la espalda, y Pablo exultante, rejuvenecido, recuperados el entusiasmo — «hay en el mundo algunas cosas perfectas, ¿no crees?, pocas pero las hay, como Le monde en periódico o el modelo lacado de Dupont»... (150).

De Gerty, a quien se nos describe como dotada de un refinamiento innato, una lánguida hauteur de reina que se manifiesta inconfundiblemente en sus manos delicadas y en el elevado arco de su pie, en la palidez cérea de su rostro, en sus ojos del azul irlandés más puro, en sus tobillos torneados $\mathrm{y}$, sobre todo, en «su riqueza de prodigiosa cabellera», —unos rizos castaños que se derraman en breve visión radiante sobre sus hombros $^{13}$ —, se nos dice que, «sentada junto a sus compañeras, sumergida en sus pensamientos, con la mirada perdida en lontananza, era, a decir verdad, un ejemplar del joven encanto irlandés tan bello como cupiera desear» (359), que «todos cuantos la conocían la declaraban hermosa» (359), y que tenía un aspecto tan delicioso en su «dulce esquividad de muchacha que, de seguro, toda la bella Irlanda, esa tierra de Dios, no con-

\footnotetext{
12 «Ella caminaba con una determinada dignidad tranquila muy característica suya pero con cuidado y muy despacio porque... porque Gerty MacDowell era... ¿Botines estrechos? No. ¡Es cojita! ¡Oh! El señor Bloom la observó alejarse cojeando. ¡Pobre chica! Por eso la dejan plantada mientras las otras corrían tanto. Me parecía que debía haber algún problema por su aire» (374). Aunque para Ochoa (1993: 789), que se refiere al extraordinario narcisismo de Gerty, no puede inferirse de su discurso que un defecto físico la afea, lo cierto es que una lectura atenta revela que ella sabe qué es lo que perturba su de otro modo impoluta belleza: «...y más de una vez la belleza de la poesía, tan triste en su hermosura transitoria, le había nublado los ojos con lágrimas silenciosas por los años que se le iban escapando uno tras otro, y si no fuera por ese defecto que ella sabía no tendría por qué temer a ninguna competidora y eso fue un accidente bajando la cuesta de Dalkey y siempre trataba de ocultarlo» (371). En su cojera ve Oviedo Moral (2003) una conexión con la Venus de Botticelli: «Venus nace del esperma de Urano, cuando sus seccionados testículos son arrojados al mar, de la misma manera que la ilusión masturbatoria de Bloom da vida a Gerty como figura idealizada y endiosada. Eso sí, imperfecta, como la Venus de Boticelli [sic], que debido al ángulo de su cadera se nos aparece con una pierna ligeramente más larga que la otra, detalle final que la relaciona plenamente con el defecto físico de Gerty» (2003: 261). Pero no debe olvidarse que, con este detalle, Joyce, para quien la vida privada constituía una fuente privilegiada de material literario, pretendía rendir homenaje a Martha Fleischmann, una jovencita coja con quien tuvo un impreciso affair entre 1918 y 1919 y a quien, según nos cuentan sus biógrafos, escribió una postal «from Odysseus to Nausicaa» (Costello, 1980: 74). Sobre este episodio en la vida de Joyce y su relación con el Ulysses, cfr., entre otros, Ellman (1982: 462-465) y Romana Paci (1970: 237-242).

13 «Jamás se vio sobre los hombros de una muchacha una cabellera más linda, más delicada, con sus rizos castaños, una breve visión radiante, en verdad, casi enloquecedora de dulzura. Habríais de viajar muchas y muchas millas antes de encontrar una cabellera como esa» (368).
} 
tenía quien se la igualara» $(360)^{14}$. Más que su belleza, lo que resaltan ambos narradores es, con todo, su extrema juventud, que en los dos casos gravita en torno a la mágica cifra de diecisiete. Joyce, así, al explicar que la ropa interior era la principal preocupación indumentaria de Gerty, la disculpa diciendo: « ¿quién que conozca las agitadas esperanzas y aprensiones de los dulces diecisiete años (aunque Gerty ya los había dejado atrás) tendría corazón para criticarla?» $(361)^{15}$; y hace reconocer más tarde a Bloom que empiezan a interesarle las jovencitas:

Me gustaría ser la piedra en que ella se sentó. Ah guapina, no sabes qué mona estabas. Empiezan a gustarme de esa edad. Manzanas verdes. Echar mano a todo lo que se ofrece. También en la biblioteca hoy: aquellas chicas graduadas. Felices las sillas debajo de ellas. Pero es el influjo del atardecer. Ellas notan todo eso. Abiertas como flores, saben sus horas, girasoles, alcachofas de Jerusalén, en salones de baile, arañas, alamedas bajo los faroles (382).

Pablo, por su parte, discursea sobre el poderío magnífico que atesoran las mujeres hermosas que no han cumplido todavía los veinte años: «Lo que parecéis ignorar las feministas, o por lo menos no lo confesáis, es que pocos individuos en el mundo gozan del grado de poder que tiene una mujer hermosa a los diecisiete años» (89). Y su amiga Elia, al observarlo de lejos en la playa junto a la hermosa desconocida, se dice a sí misma que debe de ser «una de esas muchachas hermosísimas que atesoran, según él, a los dieciocho años, aunque sólo siempre por unas horas o por unas semanas, el máximo grado de poder sobre la tierra» $(146-147)^{16}$. Porque, en efecto, si por algo se caracteriza la belleza adolescente, es por su transitoriedad. Aunque no alude a ello de forma tan extremada como Tusquets, Joyce también reflexiona sobre la brevedad de la hermosura juvenil y sobre el modo en que muy pronto toda muchacha sienta la cabeza fregando cacharros y lavando ropa, dando a luz, bañando niños y preparando, en los entierros, los cuerpos de los muertos (379).

\subsection{El juego de miradas y suposiciones mutuas}

Que, en todo caso, las jóvenes no son insensibles a los encantos de sus maduros admiradores lo pone de manifiesto el juego de miradas y suposiciones mutuas. En Varada, Pablo, que, sintiendo amainar en él el desagrado intenso que viene embargándolo en los últimos tiempos, se palpa y se examina hasta complacerse en su imagen de «hombre ma-

${ }^{14}$ El tipo de belleza de las dos jóvenes, salvo por lo que respecta a la cabellera larga y soberbia, no es el mismo, pero las diferencias pueden explicarse por la evolución del canon estético a lo largo del siglo XX.

15 Joyce le calculaba a la Nausícaa homérica unos diecisiete años, como se desprende de los comentarios del autor a Georges Borach: «On Naxos, the oldster of fifty, perhaps baldheaded, with Nausicaa, a girl who is barely seventeen. What a fine theme!». Citado por Ellman (1982: 430). En cualquier caso, Gerty no supera los veintidós. Si no, no se explicaría lo que dice a propósito de los comentarios maliciosos de sus «amigas»: «Entonces ya podrían hablar de ella hasta ponerse moradas, Bertha Supple también, y Eddy, la maligna, porque cumplía los veintidós en noviembre» (362).

${ }^{16}$ Más prosaicamente lo expresó Tusquets en una conferencia pronunciada en Chapel Hill en octubre de 1987 bajo los auspicios de la Universidad de North Carolina: «... como dice un canon de belleza, en la mujer, la belleza termina entre los veintiuno y los veintidós, y en el hombre termina a los ochenta.» (1989: 85). 
duro, todavía fuerte y atractivo (...) con cierto aire, eso sí, de desencanto y de fatiga», piensa:

y a lo mejor les ha parecido incluso interesante a las dos chicas, que se han levantado de la mesa y avanzan hacia el mar a través de la playa, y no se han dado vuelta una sola vez para mirarle, aunque es muy probable que le hayan estado espiando a hurtadillas, posible asimismo que desarrollen en su honor (nadie más puede verlas) esa mágica pantomima a orilla de las olas, la cabeza hacia atrás, el largo pelo llegándoles casi a la cintura, los ojos entrecerrados, los brazos extendidos, y luego han dado vueltas y se han cogido por los hombros y han entrado las dos enlazadas en la mar, absolutamente conscientes (ahora sí está Pablo seguro) de su espléndida belleza erguida al sol de la mañana, absolutamente ciertas de que este tipo interesante, con la pipa y las sienes plateadas, no les quita ojo de encima (137-138).

También en el Ulysses, Gerty, cuando se quita el sombrero para arreglarse el pelo, es perfectamente consciente del tumulto que ha provocado en Bloom: «casi pudo ver el rápido destello en respuesta admirativa de los ojos de él, que la hizo vibrar en todos sus nervios» (368). Bloom, por su parte, se dice a sí mismo al final del capítulo: «Apuesto a que se dio cuenta de que yo. Cuando alguien se siente así muchas veces se encuentra con lo que siente. ¿Le gusté o qué? Al traje es a lo que miran. Siempre saben cuando uno les hace la corte» (376). Pero, si las motivaciones de la muchacha pelirroja no llegan a desvelarse ${ }^{17}$, el lector del Ulysses sabe bien que a Gerty, aficionada a asimilarse a los personajes de las novelas sentimentales que tanto le gustan, lo que le conmueve son sus ojos oscuros y su pálido rostro intelectual, sus ropas de luto, el hecho de que en su rostro estuviera escrita la historia de un dolor acosador: «ella se atrevió a mirarle y la cara que se ofreció a su mirada allí en el crepúsculo, consumida y extrañamente tensa, le pareció la más triste que había visto jamás» (365).

\subsection{La cursilería conmovedora de la muchacha}

Es interesante subrayar, por otro lado, que tanto la joven de Tusquets como la de Joyce se caracterizan por su cursilería, por el pésimo gusto con que decoran su apartamento o por los trastos feos de los que está llena su habitación. En el cajón del tocador de Gerty, «escondite de sus tesoros de muchachita», encontramos «las peinetas de tortuga, la medalla de Hija de María, el perfume rosa blanca, la cejaleína, el portaperfumes de alabastro, las cintas para cambiar cuando le llegaban sus cosas de lavar» (371), y un álbum de confesiones de cubiertas rosa coral que le regaló una amiga, en el que ha escrito con tinta violeta «algunos hermosos pensamientos» extraídos de periódicos viejos. También el refugio veraniego de la chica pelirroja con la que se entusiasma Pablo es «una casa llena de plantas y flores y carteles y cachivaches», algunos muy «feos»y, «encima de la cama, apoyado en la almohada, un apolillado y polvo-

17 «"Qué haces aquí conmigo, si es seguro que todos los chicos del pueblo están deseando sacarte de paseo?", y ella se encoge de hombros, "te quiero a ti”, y Pablo "eres una loca, una tipa loca, ¿por qué me quieres?, di, por qué me quieres", muriéndose de ganas de que se lo explique y escucharlo, pero la muchacha vuelve a encogerse de hombros, a reír, a parpadear inquieta y no se arriesga a decir nada» (168). 
riento oso de peluche» (199), algo que, en vez de desagradarle, le conmueve y enternece.

\subsection{La despedida}

Pablo, en fin, cuando se ve obligado a abandonar a la chica, le explica «que no pueden continuar, que ha sido muy hermoso, inolvidable (y la chica no podrá saber hasta qué punto ha sido exacto y sincero al decir inolvidable), lo que han vivido juntos, pero que ha tocado a su fin», mientras ella «llora y llora sin despegar los labios y asiente con un gesto de cabeza a todo lo que él argumenta, a todo lo que él asesina, a todo lo que Pablo caballerosamente, canallescamente, cobardemente traiciona» (368). Bloom, de modo paralelo, se dice: « $¡ A$ Ah! Esa hembra me ha dejado agotado. Ya no soy tan joven. ¿Vendrá mañana aquí? Esperarla en algún sitio para siempre. Debe volver. Los asesinos vuelven. ¿Volveré yo?» $(386)^{18}$. Y, pensando que todo mensaje que le deje sobre la arena ha de borrarse inevitablemente se dirige a ella en su imaginación diciendo: «No volveremos a encontrarnos. Pero ha sido estupendo. Adiós, guapa. Gracias. Me ha hecho sentirme muy joven». El tono de Pablo es, en todo caso, más trágico, porque sabe que, a fin de cuentas,

el perdedor es él, que se ha perdido a sí mismo o a cierta parte muy querida de sí mismo sin remedio, que la vida le ha dado, a fuer de generosa o de perversa, una última oportunidad, y tampoco ha sido esta vez capaz de aprovecharla, y no ha de haber ya otras, y es, ahora sí, el definitivo final donde se entierra para siempre, junto a la juventud, la posibilidad de soñar y levantar el vuelo (228).

Son varios, por tanto, los paralelos conceptuales y formales que aquí documentamos, como los binomios «que no pueden continuar» / «no volveremos a encontrarnos»; «ha sido muy hermoso» / «ha sido estupendo» o las responsiones léxicas señaladas en cursiva.

\section{LA RECEPCIÓN DEL ULYSSES POR ESTHER TUSQUETS: DECLARACIONES DE LA AUTORA}

Las reglas básicas mediante las cuales puede establecerse, en presencia de pasajes paralelos de dos autores, la dependencia de uno con respecto al otro, son, según Highet,

18 ¿Quién es asesino y quién víctima? Las respuestas de la crítica divergen tanto que corresponde al lector concluir a quién culpar —o determinar si realmente es preciso culpar a alguien — en el episodio erótico GertyBloom. Muchos críticos aluden todavía a la relación Gerty-Bloom «as one of victim and victimizer, symptom and disease, effect and cause» (Bishop, 1999: 186). Se ha subrayado así, por lo general, la inconsciencia de Gerty (Weinstein, 1996: 115). Otros han afirmado que a quien debe culparse es a Bloom, que no sólo aprovecha el espectáculo que le brinda la muchacha para autosatisfacerse, sino que, además, se refiere con crueldad a su defecto físico: «Bloom leaks the painful secret of Gerty's lameness, then says with uncharacteristic cruelty, "Glad I didn't know it when she was on show" calling her a "curiosity"» (McLean, 1998: 54). Por otra parte, hay quienes han dejado de considerar a la muchacha víctima inocente de la perversión de Bloom. McGee alega, por ejemplo, que Gerty «is able to manipulate the system of sexual values, to employ its symbols and discursive practices, to achieve her own pleasure» (1996:125). La joven aparece, de todos modos, como una «pathetic victim of social and religious enculturation» (Henke, 1982: 132). En este sentido, el personaje sería una lolita avant la lettre. Sobre la relación de Gerty con Lolita, cfr. Cornwell (2005, en prensa). 
tres (1949: 202). En primer lugar hay que demostrar que un escritor leyó la obra de otro, o que pudo haberla leído; en segundo lugar, que existe una estrecha semejanza de pensamiento o de imágenes; en tercer lugar, que se da un evidente paralelismo estructural, una analogía en el hilo del razonamiento, en la configuración de las cláusulas o en la colocación de las palabras dentro de los versos ${ }^{19}$. Como a los dos últimos requisitos nos hemos referido en el apartado anterior, aquí vamos a centrarnos en el primero: ¿leyó Esther Tusquets el Ulysses de Joyce? En caso de que lo leyera, ¿lo hizo en versión original o en traducción?

Sabemos, para empezar, que en 1980, coincidiendo con la publicación de Varada, la editora y novelista catalana, entrevistada por Víctor Claudín, se permitía afirmar sobre Joyce lo siguiente:

Joyce me tiene preocupada últimamente... no sé... no creo que sea sólo estilo, parece que quiere contar, es al menos la impresión que me produce a mí. Quiere y no quiere... me tiene irritada por el hecho de que no contara más... de que no hiciera otro Ulises, porque está claro que tenía muchas cosas para contar. Y no puedo con el pudor... eso es... como un pudor a contar. (1980: 48)

En 1983, al listar en la revista Quimera los quince libros más importantes del siglo XX, Tusquets incluía entre ellos el Ulysses; y, poco después, confesaba a Geraldine Nichols que de la literatura inglesa, que normalmente lee en traducción, los autores que más le interesaban eran Virginia Woolf y James Joyce, sobre todo Joyce, de cuyas obras destacaba, además de la brillantez estilística, el contenido humano:

De Joyce lo que siempre se te dice: que la experimentación con el lenguaje, y la maravilla estilística del Ulises: pero luego te das cuenta que la información que da sobre las cosas humanas y personales también es muy interesante. La riqueza formal te enmascara el otro (1989: 73$)^{20}$.

Esther Tusquets, pues, aunque fuera en traducción, conocía de cerca el Ulysses, ya que se permitía opinar públicamente sobre él ${ }^{21}$. Y no sólo eso, puesto que fue Lumen, editorial de su propiedad, la que sacó a la luz la traducción española de esta obra llevada a cabo por Valverde, regalo que le hizo la empresaria Carmen Balcells durante un cóctel. En sus memorias, tituladas Confesiones de una editora poco mentirosa, publicadas en 2005, nos cuenta:

Muy en los comienzos de la nueva colección de narrativa de Lumen (...) Carmen Balcells me hizo un regalo tan enorme como inesperado (creo que inesperado incluso para ella: creo que fue un arrebato de repentina y arbitraria generosidad, ese placer de jugar a los Reyes Magos, que conozco muy bien porque era también una característica de mi padre). «¿Cuál es el

${ }^{19}$ Cfr. también Alonso (1963). Completan estas apreciaciones Cristóbal (1992) y Laguna (1994).

${ }^{20}$ Aunque el libro, que recoge una serie de entrevistas a escritoras españolas contemporáneas, se publicó en 1989, las declaraciones de Tusquets datan del 3 de junio de 1984 y del 20 de junio de 1985.

${ }^{21}$ Contamos, además, con el testimonio de M. Pesarrodona, amiga de Tusquets, quien comenta que, si no la traiciona la memoria, la novelista leyó el Ulysses en la versión de J. Salas Subirat durante un verano que pasó en la Suiza alemana (2004: 13). 
autor y la obra más importante de la narrativa contemporánea? Me preguntó de sopetón. «Pues no sé...» ¿Cuál te gustaría editar?» Vacilé unos momentos y finalmente, por decir algo, «Ulises, James Joyce» «Pues te daré toda la narrativa de Joyce». Quedé sin aliento, a punto estuve de caer desmayada sobre la mullida alfombra del elegante hotel (2005: 78-79).

No cabe duda de que, por referirnos a verdades humanas tan generales, todo podría ser fruto de la casualidad. Tal vez la belleza deslumbrante de las jóvenes sea tópica, quizás el juego de miradas y suposiciones es mera casualidad, tal vez la cursilería es un rasgo común a muchas adolescentes, tal vez muchos hombres maduros encuentran en una jovencita el camino hacia su propia juventud perdida, quizá la orilla del mar es el escenario mágico en que este ritual puede cumplirse mejor ${ }^{22}$. Pero los comentarios que realiza Tusquets sobre el contenido humano del Ulysses, la abundancia de paralelos estructurales y el hecho de que encontremos algunos ecos verbales de la traducción de Valverde, dada a conocer por ella misma en Lumen sólo cuatro años antes de la publicación de su novela, nos debe llevar, cuando menos, a cuestionarnos que exista un vínculo efectivo entre el Ulysses y Varada ${ }^{23}$.

Y ello, a su vez, debería llevarnos a reflexionar sobre la recepción del Ulysses en las letras hispánicas contemporáneas, estudio por el que clamaba, ya en 1994, Julio M. de la Rosa. El escritor y crítico literario llamaba la atención sobre el hecho de que, en las largas y polémicas conversaciones que mantuvo en su juventud con los novelistas de la década de los cincuenta ${ }^{24}$, éstos nunca mencionaban a Joyce como influencia o lectura fundamental, y concluía planteándose, por ello, que tal trabajo acabaría siendo la «crónica de una indagación inútil», y la tan comentada presencia de Joyce en la narrativa contemporánea, «más reverencial que real» (1994: 16). Que Esther Tusquets, aunque fuera con reservas, admiraba a Joyce se infiere fácilmente de sus declaraciones. En estas páginas esperamos haber demostrado que esa admiración no fue sólo reverencial.

${ }^{22}$ Pensemos, por ejemplo, en el «Himno a la juventud» (Poemas póstumos, 1968) de Jaime Gil de Biedma, en que una jovencita surgida del mar suscita la desazón en el yo lírico que la contempla, pero también el deseo de una vida más intensa y más libre: «Estábamos tranquilos los mayores / y tú vienes a herirnos, reviviendo / los más temibles sueños imposibles, / tú vienes para hurgarnos las imaginaciones. / De las ondas surgida, / toda brillos, fulgor, sensación pura / y ondulaciones de animal latente, / hacia la orilla avanzas / con sonrosados pechos diminutos, / con nalgas maliciosas lo mismo que sonrisas, / oh diosa esbelta de tobillos gruesos, / y con la insinuación / (tan propiamente tuya) / del vientre dando paso al nacimiento / de los muslos: belleza delicada, / precisa e indecisa, / donde posar la frente derramando lágrimas. / Y te vemos llegar - figuración / de un fabuloso espacio ribereño / con toros, caracolas y delfines, / sobre la arena blanda, entre la mar y el cielo, / aún trémula de gotas, / deslumbrada de sol y sonriendo. / Nos anuncias el reino de la vida, / el sueño de otra vida, más intensa y más libre, / sin deseo enconado como un remordimiento...».

23 Abona esta hipótesis el hecho de que en El mismo mar de todos los veranos (1978: 201), primera novela de la trilogía, la autora equipare con el retorno de Ulises a Ítaca el regreso a casa del marido de la protagonista, famoso director de cine que tiene, en los puntos más insospechados de la tierra, constantes aventuras con muchachas rubias, pelirrojas o castañas, de cabello liso o rizado, de ojos y pieles de todos los colores, pero invariablemente jóvenes, invariablemente hermosas, invariablemente provistas, como la muchacha de Varada, de anchos hombros y de largas piernas.

${ }^{24}$ Cita, entre otros, a I. Aldecoa, R. Sánchez Ferlosio, C. Martín Gaite, J. Goytisolo, A. M. Matute, J. García Hortelano y J. M. Caballero Bonald. 


\section{BIBLIOGRAFÍA}

Alonso, D. «¿Tradición o poligénesis?» Boletín de la Biblioteca Menéndez Pelayo XXXIX (1963): 5-27.

BERNÁldEZ BERNÁLdeZ, J. M. «Ulises, traducido» Cuadernos hispanoamericanos 319 (1977): 204-208.

Bigatel AbenaCaR, B. L. «Nausicaa: a Question of Duality» Papers on Joyce 6 (2000): 3-8.

BishoP, J. «A Metaphysics of Coitus in "Nausicaa”» Ulysses (En)Gendered perspectives: Eighteen New Essays on the Episodes (Cultural Frames, Framing Culture). Ed. K. J. Devlin and M. Reizbaum. University of South Carolina Press, 1999. 185-209.

Budgen, F. James Joyce and the Making of Ulysses and Other Writings, London-Oxford-Melbourne: Oxford University Press, 1972.

CAmps, A. «Entre la mueca y el artificio: el uso de la parodia en el Ulises de James Joyce» La parodia y el viaje imaginario. Actas del IX Simposio de la Sociedad Española de Literatura General y Comparada. Ed. T. Blesa, M. T. Cacho, C. García Gual, M. Rolland, L. Romero Tobar y M. Smerdou Altolaguirre. Zaragoza: Universidad de Zaragoza, 1994. vol. 2. 65-71.

CANEDA CABRERA, M. T. «Ulysses and Heteroglossia: a Bakhtinian Reading of the "Nausicaa" Episode» Revista Alicantina de Estudios Ingleses 9 (1996): 33-40.

Claudín, V. «Esther Tusquets: Conquista de la felicidad» Camp de l'arpa 71, (enero 1980): 47-49.

Cornwell, N. «Ulysses and Lolita» James Joyce Broadsheet 71 (June 2005): 1.

—, «Intimations of Lo: Sirens, Joyce and Nabokov's Lolita» Festschrift in Honour of Vittorio Stra$d a$. Eds. Bocharov and Sutar (en prensa).

Costello, P. James Joyce, Dublin: Gill and Macmillan, 1980.

CRISTóBAL, V. «Odi et amo: textos paralelos en Ausias March» Actes del Xè Simposi de la Secció Catalana de la SEEC, Tarragona, 28-30 Novembre 1990, Homenatge a Joseph Alsina II, Tarragona, 1992. 361-367.

Devlin, K. «The Romance Heroine Exposed: "Nausicaa" and The Lamplighter» James Joyce Quarterly 22.4 (1985): 383-396.

Ellman, R. James Joyce, New Cork-London-Toronto: Oxford University Press, 1959 (edición revisada, 1982).

—, The Consciousness of Joyce, London: Faber \& Faber, 1977.

FRENZEL, E. Diccionario de argumentos de la literatura universal, Madrid: Gredos, 1994.

García Tortosa, F. «Las traducciones de Joyce al español» Joyce en España (I). Eds. F. García Tortosa y A. R. de Toro Santos, Universidade da Coruña, 1994. 19-29.

HENKE, S. «Gerty MacDowell: Joyce's Sentimental Heroine» Women in Joyce. Ed. S. Henke y E. Unkeless, Urbana: University of Illinois Press, 1982. 132-149.

—, «Joyce's Naughty Nausicaa: Gerty MacDowell Refashioned» Papers on Joyce 10/11 (20042005): 85-104.

HigGINS, L. «"Lovely Seaside Girls" or "Sweet Murderers of Men”? Fatal Women in Ulysses» Gender in Joyce. Ed. J. W. Wawrzycka y M. G. Corcoran, Gainesville: University Press of Florida, 1997. 47-61.

HigHET, G. Greek and Roman Influences on Western Literature. New York-Oxford: Oxford University Press, 1949 (reimpresión de 1985).

JACQUET, C. (1974) «Les plans de Joyce pour Ulysse» Ed. L. Bonnerot et alii, Ulysses cinquante ans après. Témoignages franco-anglais sur le chef-d'oeuvre de James Joyce, Paris, Didier.

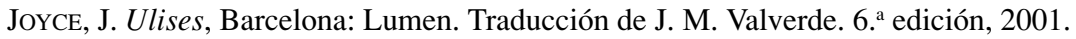

KuPINSE, W. «Household Trash: Domesticity and National Identity in The Lamplighter and the “Nausicaa” Episode of Ulysses» The South Carolina Review 32.1 (1999): 81-87. 
LaGUNA MARISCAL, G. «Literatura comparada y Tradición Clásica: Quevedo y sus fuentes clásicas» Anuario de Estudios Filológicos 17 (1994): 283-293.

Law, J. D. «"Pity They Can't See Themselves": Assessing the "Subject" of Pornography in "Nausicaa"» James Joyce Quarterly 27.2 (1990): 219-239.

LeCKIE, B. «Reading Bodies, Reading Nerves: "Nausicaa" and the Discourse of Censorship» James Joyce Quarterly 34.1/2 (1996): 65-85.

McGeE, P. «Joyce's Nausea: Style and Representation in "Nausicaa” James Joyce Quarterly 24.3 (1987): 305-318.

—, «When Is a Man not a Man?: Or, The Male Feminist Approaches "Nausicaa"» Joyce in the Hibernian Metropolis, Columbus, Ed. M. Beja and D. Norris. Ohio: Ohio State University Press, 1996. 122-127.

McLean, C. D. «Wasted Words: The Body Language of Joyce's Nausicaa» Joycean Cultures. Culturing Joyces, Ed. V. J. Cheng, K. J. Devlin, M. Norris. University of Delaware Press, 1998. 44-58.

Nichols, G. C. Escribir: espacio propio. Laforet, Matute, Moix, Tusquets, Riera y Roig por sí mismas, Minneapolis : Institute for the Study of Ideologies and Literature, 1989.

NoRRIS, M. «Modernism, Myth, and Desire in "Nausicaa"» James Joyce Quarterly 26.1 (1998): 37-50.

OchOA, P. «Joyce's "Nausicaa”: The Paradox of Advertising Narcissism» James Joyce Quarterly 31.1 (1993): 783-793.

Oviedo Moral, F. «Una aproximación cubista a "Nausicaa"» Silverpowdered Olivetrees. Reading Joyce in Spain, Eds. Simons J., J. M. Tejedor Cabrera, M. Estévez Saá y R. I. García León. Sevilla: Secretariado de Publicaciones de la Universidad de Sevilla, 2003. 257-263.

Pearce, R. «"Nausicaa": Monologue as Monologic» Joyce in the Hibernian Metropolis. Ed. M. Beja and D. Norris, Columbus. Ohio: Ohio State University Press, 1996. 106-114.

Pesarrodona, M. «Un siglo de modernidad (literaria)» El País. Babelia (12/VI/04): 13.

POTTER, R. «Can my daughter of 18 read this book: Ulysses and obscenity» en Critical Quarterly 46.4 (2004): 22-37.

Romana PaCi, F. James Joyce. Vida y obra, Barcelona: Edicions 62, 1970. [Traducción de J. Montserrat Torrents].

RosA, J. M. de la «James Joyce en España» Joyce en España (I). Eds. F. García Tortosa y A. R. de Toro Santos. Universidade da Coruña, 1994. 13-17.

Schwarze, T. T. Joyce and the Victorians, Gainesville: University Press of Florida, 2002.

SERRANO-SORdo, M. «Usos de Homero y parodia en el Ulysses de James Joyce (Capítulos 12 y 13, "Cíclope" "Nausicaa")» La parodia y el viaje imaginario. Actas del IX Simposio de la Sociedad Española de Literatura General y Comparada, Ed. T. Blesa, M.T. Cacho, C. García Gual, M. Rolland, L. Romero Tobar y M. Smerdou Altolaguirre, Zaragoza: Universidad de Zaragoza, vol. 2. 251-256.

SICKER, P. «"Alone in the Hiding Twilight": Bloom's Cinematic Gaze in "Nausicaa"». James Joyce Quarterly 36.4 (1999): 825-850.

SмIтн, C. «Twilight in Dublin: A Look at Joyce's “Nausicaa”» James Joyce Quarterly 29.1 (1991): 631-635.

SмIтH, C. S. «Joyce's Ulysses: Dimensions of the Sacred at Sandymount». English Language Notes 27.4 (1990): 57-63.

STANFORD, W.B. The Ulysses Theme. A Study in the Adaptability of a Traditional Hero, Oxford: Basil Blackwell, 2' edición, 1963.

STEINER, W. «"There Was Meaning In His Look": The Meeting of Pictorial Models in Joyce's "Nausicaa"» Studies in Literature 16.2/3 (1984): 90-103.

StUART, G. James Joyce's Ulysses, London: Faber and Faber, Ltd., 1930; New York: Alfred A. Knopf, 1931 (revised edition, 1952). 
TUSQUETS, E. «Los libros del siglo» Quimera 30 (Abril 1983): 5.

—, «Para salir de tanta miseria» Ojáncano 2 (Abril1989): 73-85.

-, El mismo mar de todos los veranos, Anagrama, Barcelona, 1990 (3. a edición, 1997).

- Varada tras el último naufragio, Anagrama, Barcelona, 1998.

- Confesiones de una editora poco mentirosa, Barcelona: Rquer, 2005.

VALVERDE, J. M. Joyce, Barcelona: Barcanova, 1982.

Weinstein, P. «For Gerty Had Her Dreams That No-one Knew Of» Joyce in the Hibernian Metropolis, Ed. M. Beja and D. Norris. Columbus, Ohio: Ohio State University Press, 1996. 115121. 